\title{
Quincuagésimo Aniversario
}

Durante mis años de formación, y en mi vida profesional, fui consciente de la necesidad de referirme a lo que se está investigando en el país y en otras instituciones a nivel mundial, con el fin de mantenerme actualizada, tanto para preparar mis cursos, como para enterarme de las problemáticas estudiadas por otras instituciones y para identificar grupos afines a los proyectos de investigación que se llevaban a cabo en nuestra Facultad de Medicina Veterinaria, FMVZ. Lo anterior me llevó a reconfirmar todavía más, que el quehacer científico debe siempre tener como fin el que sea de beneficio para los seres vivientes y que es fundamental que, sus resultados, sean conocidos a través de los diversos medios de difusión disponibles.

A fines de los años sesenta un grupo de colegas entusiastas nos dimos a la tarea de fundar una revista en la cual se pudiesen publicar, con rigor científico, las diversas investigaciones que se generaban en nuestra querida FMVZ y también aceptar trabajos de otras instituciones. No fue un trabajo fácil, ya que, como todo proyecto, tuvimos que convencer a colegas y directivos de los grandes beneficios que una revista de este tipo tendría, como la de difundir los resultados de nuestros proyectos de investigación y darle una gran presencia a la FMVZ como generadora de conocimiento de actualidad.

Fue así que en 1970, nace la revista Veterinaria México que ha sobrevivido ya 50 años manteniendo su reconocida calidad. En ella se han publicado cientos de artículos científicos, notas de investigación, artículos de revisión y por invitación. La revista ha transitado de ser publicada en español a ser ahora publicada en inglés. Es reconocida por índices nacionales como el CONACyT e Internacionales como JCR. Se dice fácil, pero ha sido el producto del esfuerzo de muchos colegas, que se han comprometido con la revista, enviando sus publicaciones, participando en los comités editoriales y promoviéndola y difundiéndola.

La comunidad Universitaria y en especial la de la FMVZ se debe sentir muy orgullosa de este logro. Mi más sincero reconocimiento a todos los que han colaborado con este gran proyecto. Festejemos y disfrutemos estos 50 años y trabajemos para que esta revista continúe difundiendo el quehacer científico por muchos años más. 